\title{
A GESTÃO COLABORATIVA DA MARCA NAS REDES SOCIAIS VIRTUAIS
}

\section{Clóvis Reis}

Doutor em Comunicação pela Universidad de Navarra Docente da Universidade de Blumenau FURB

E-mail: clovis@furb.br (Brasil)

\section{Fabrícia Durieux Zucco}

Doutoranda em Administração pelo PMDA da Universidade Nove de Julho - UNINOVE Docente da Universidade de Blumenau - FURB

E-mail: fabricia@furb.br (Brasil)

\section{Joana Dambrós}

Bacharel em Publicidade pela Universidade de Blumenau - FURB

E-mail: nutsjo@gmail.com (Brasil)

\section{RESUMO}

A partir do conceito de aprendizagem colaborativa ou cooperativa (processo educacional baseado no trabalho em conjunto, no compartilhamento de informações e na interdependência dos membros do grupo), o presente artigo discute a proposta de gestão colaborativa da marca nas redes sociais virtuais. Na gestão colaborativa, a estratégia de comunicação das empresas evolui do modelo de um a muitos para o modelo de muitos a muitos, numa linha de ação horizontal e em via de mão dupla.

Palavras-chave: Gestão Colaborativa; Internet; Marca; Propaganda; Redes Sociais Virtuais.

REMark - Revista Brasileira de Marketing, São Paulo, v. 8, n. 2, p 41-54, jul./dez. 2009. 


\section{INTRODUÇÃO}

O advento da Web 2.0 (termo que designa o atual estágio de desenvolvimento da web como uma plataforma de trabalho baseada na participação dos usuários) e das redes sociais virtuais (espaços e ferramentas que promovem a formação de comunidades e o intercâmbio social na rede, tais como Orkut, MySpace, Facebook, YouTube etc.) cria um novo cenário para a relação dos consumidores com as marcas. Os consumidores não se contentam simplesmente em receber informações, mas buscam a interação com a marca, gerando conteúdos que desafiam as práticas tradicionais da comunicação de marketing.

Nesse cenário de transformações da $w e b$, no qual se destacam os conteúdos gerados pelo usuário (CGU), a comunicação rapidamente evolui dos modelos um a um e um a muitos para o modelo de muitos a muitos, um processo de comunicação de muitos emissores, muitos receptores e uma quantidade muito maior de intercâmbios e de cooperação. Em suma, trata-se de um modelo de comunicação que substitui o monólogo pelo diálogo, a comunicação unidirecional, em ambiente controlado e de cima para baixo, pela comunicação horizontal e em via de mão dupla.

O presente trabalho analisa o impacto de tais mudanças para a gestão da imagem das marcas, o relacionamento e a comunicação com os consumidores. A partir da ideia de aprendizagem colaborativa ou cooperativa (processo educacional baseado no trabalho em conjunto, no compartilhamento de informações e na interdependência dos membros do grupo), o artigo discorre sobre o conceito de gestão colaborativa da marca nas redes sociais virtuais.

Trata-se de uma primeira aproximação teórica ao tema. $\mathrm{O}$ trabalho enquadra-se no que se denomina artigo de revisão, isto é, resume, analisa e discute informações já publicadas. Desde uma perspectiva geral, apresenta um panorama introdutório sobre o tema que discute, entendendo-se sua proposta como parte de uma fundamentação teórica mais ampla e que se encontra em marcha. Nesse percurso, realiza uma revisão bibliográfica na qual são valorosas as contribuições de autores como Castells (1999), Lévy (1999), O’Reilly (2007) e Romaní e Kuklinski (2007).

REMark - Revista Brasileira de Marketing, São Paulo, v. 8, n. 2, p 41-54, jul./dez. 2009. 


\section{POSICIONAMENTO DA MARCA}

O surgimento da marca data de tempos remotos, quando o aumento da distância entre fornecedor e consumidor tornou-se uma barreira para os negócios. Os símbolos eram utilizados para identificar utensílios e indicar sua proveniência. Para a American Marketing Association (2007), marca é o conjunto de elementos (tais como nome, imagem, desenho, termo ou outra característica) que diferencia o produto de um determinado fornecedor em comparação com o mesmo produto que os demais fornecedores oferecem.

Uma marca tem valor na medida em que o símbolo adquire um significado exclusivo, que se sobressai, associado a características tangíveis e satisfações imateriais psicológicas ou sociais (KAPFERER, 2003). O processo de dotar uma marca de valor é chamado de branding. Ele permite ensinar aos consumidores quem é o produto, a que se presta e por que o consumidor deve se interessar por ele (KOTLER; KELLER, 2006). Identidade de marca é a forma como se emite tal significado ao público-alvo, e deve ajudar a estabelecer o relacionamento entre a empresa e o cliente, por meio de uma proposta de valor envolvendo benefícios funcionais, emocionais ou de autoexpressão (AAKER, 2007).

A identidade da marca está intimamente ligada ao seu posicionamento no mercado, isto é, ao modo como projeta o produto e a empresa, a fim de que ocupem um lugar de destaque na mente do consumidor, maximizem a vantagem potencial da empresa e criem motivos convincentes para que o consumidor adquira o produto (KOTLER; KELLER, 2006).

Posicionamento não é o que se faz com o produto, mas o que se faz na mente do consumidor para que ele passe a perceber um produto ou marca de uma determinada forma (RIES; TROUT, 1996). O posicionamento realinhava as conexões que já existem na mente do consumidor. Porém não dura para sempre, ainda que os principais atributos, importantes para a maioria dos clientes, continuem os mesmos. Devido às mudanças nos hábitos dos consumidores, na posição dos concorrentes, nos avanços da tecnologia e nas oscilações da economia, as empresas devem permanentemente avaliar o posicionamento das suas principais marcas (KOTLER, 2003).

O conceito de posicionamento é fundamental para a gestão da marca, pois determina as diretrizes básicas que ela seguirá. Desse modo, o posicionamento se estende a todos os ativos da marca.

REMark - Revista Brasileira de Marketing, São Paulo, v. 8, n. 2, p 41-54, jul./dez. 2009. 


\section{GESTÃO DA MARCA}

A gestão da marca compreende o gerenciamento de todos os ativos que contribuem para sua formação. Esse processo vai muito além da identidade e da propaganda, estendendo-se ao público interno, aos intermediários e ao consumidor final. Como o modelo empresarial do novo milênio se centra na importância das pessoas, seu conhecimento é muito importante para quem administra uma marca, já que isso afeta diretamente a sua receptividade.

Dentro de uma empresa, é a atuação das pessoas que cria posição de liderança sobre a concorrência, em um cenário no qual grande parte dos produtos foi reduzida a commodities (ELLWOOD, 2004). Portanto já não é possível considerar a gestão de marca um domínio exclusivo da área ou do departamento de marketing. Todos os funcionários devem entender as metas e os valores da empresa e transpirá-los em seu trabalho diário. Isso exerce enorme influência sobre a marca no meio exterior, garantindo uma gestão eficaz.

Assim, é imprescindível o conhecimento profundo dos consumidores, condição determinante para o desenvolvimento bem-sucedido de percepções e atitudes relacionadas a um produto ou serviço, levando a um comportamento positivo em relação à marca (STONE; WOODCOCK, 1998).

Entre as novas ferramentas utilizadas na construção e na manutenção de marcas, a internet, embora recente, se mostra importante. O uso da tecnologia digital e do poder das redes de computadores permite a criação de uma forma muito eficaz de marketing, que vem se tornando rapidamente uma parte fundamental da atividade empresarial.

Nesse sentido, Aaker e Joachimsthaler (2007) destacam três razões para a presença da marca na internet: a rede é um meio interativo e envolvente, oferece informações valiosas e atualizadas, e personaliza a comunicação. Os autores ponderam que a marca já não está segura atrás de cordões de isolamento. Ela caminha entre as pessoas, público ativo que interfere no seu deslocamento, criando uma situação que envolve riscos e oportunidades.

Desse modo, a criação de ações que contribuam para a construção de marcas na web requer novas perspectivas e habilidades, além da vontade de compreender suas propriedades singulares, tais como interação, envolvimento, informações atualizadas e experiência personalizada.

REMark - Revista Brasileira de Marketing, São Paulo, v. 8, n. 2, p 41-54, jul./dez. 2009. 


\section{RELACIONAMENTO COM O CONSUMIDOR}

Surgido nos anos 1990, a partir do momento em que o consumidor passou a ser mais exigente em relação às empresas e a individualizar-se, ao invés de massificar-se, o relacionamento com o consumidor tornou-se uma peça-chave no desenvolvimento da empresa e da marca.

Stone e Woodcock (1998) definem marketing de relacionamento como o uso das ferramentas de marketing já existentes, porém direcionadas para a identificação individual e nominal dos clientes, a criação de um relacionamento entre a empresa e os clientes, e a administração desse relacionamento em benefício de ambos. Tal processo centra-se nas pessoas e requer o cultivo do relacionamento certo com o grupo certo (KOTLER; KELLER, 2006).

O marketing de relacionamento não é uma ação isolada dentro de uma empresa, mas envolve a reorientação das políticas dos vários setores da organização. Todos precisam estar alinhados com a imagem da empresa. Trata-se de um compromisso contínuo e de longo prazo, que constitui um conjunto de desafios permanente, assim como manter os clientes antigos, aprender com os erros passados e melhorar os relacionamentos com atuais e novos clientes.

O marketing de relacionamento aproveita diversas ferramentas, especialmente as que constituem o marketing direto, para comunicar-se com o consumidor. Atualmente, os computadores e softwares de database marketing viabilizam o tratamento individualizado, através do estabelecimento dos bancos de dados e preferências do consumidor, favorecendo o Gerenciamento do Relacionamento com o Consumidor (CRM).

O CRM pressupõe que os clientes tomam suas decisões de compra baseados no relacionamento que têm com seus fornecedores (BRETZKE, 2000), o que ficou mais fácil graças à evolução das tecnologias da informação. O que o consumidor deseja é reconhecimento, valor, qualidade e respeito em troca de sua preferência. Assim, deve-se entender o CRM como o gerenciamento da empresa com base nas relações que mantém com os clientes (CENTURIÃO, 2001).

A experiência anterior que o consumidor teve com uma marca ou empresa é um dos fatores mais importantes no relacionamento entre ambos (STONE; WOODCOCK, 1998). A percepção é resultado de influências. Comparações são inevitáveis. Por isso é importante estar atento às experiências do consumidor com serviços, marcas ou empresas, já que isso produzirá reflexos das mais diversas formas.

Expectativas cada vez maiores do consumidor afinado com a tecnologia ganham impulso, na

REMark - Revista Brasileira de Marketing, São Paulo, v. 8, n. 2, p 41-54, jul./dez. 2009. 
medida em que a infraestrutura eletrônica possibilita e dissemina a interatividade entre produtores e consumidores. Tal tendência impõe novas condições no relacionamento com os clientes - a troca do monólogo (da empresa para o consumidor) pelo diálogo (entre empresa e consumidor) - e potencializa a fidelidade à marca (MCKENNA, 1998).

\section{REDES SOCIAIS VIRTUAIS}

A Web 2.0, como O’Reilly (2005) define o atual estágio de desenvolvimento da rede, é vista como uma grande revolução no meio digital, pois seus recursos simplificam a leitura, a produção e o compartilhamento de conteúdos nos mais diversos formatos. Romaní e Kuklinski (2007) sublinham que tais recursos vão rapidamente angariando adesão dos usuários, que organizam, classificam e hierarquizam a informação e o conhecimento explícito de maneira coletiva. Nesse sentido, aponta-se que as aplicações 2.0 possuem sete princípios de construção:

- A web transforma-se em plataforma de trabalho.

- A web estimula o desenvolvimento de uma inteligência coletiva, com a geração conjunta de conteúdos. - A web propicia experiências enriquecedoras, com a possibilidade de intercriação e participação ativa dos usuários.

- A web cria valor ao conteúdo que gera.

- A web oferece modelos de programação rápida, porque a arquitetura da informação segue uma estrutura simplificada.

- Na web, o software não fica limitado a um dispositivo e o computador perde o status de única possibilidade de acesso aos dados.

- A web decreta o fim do ciclo de atualizações de software, disponibilizando versões experimentais online.

A real importância da Web 2.0 não está nas suas características conceituais e técnicas, mas sim em seus projetos. Trata-se da evolução constante dos meios, não de um marco estático. É o que caracteriza, juntamente com a infraestrutura material, o universo de informações abrigadas pela web, o ciberespaço, assim chamado por Lévy (1999). Castells (1999) acrescenta que não é a

REMark - Revista Brasileira de Marketing, São Paulo, v. 8, n. 2, p 41-54, jul./dez. 2009. 
centralidade de conhecimentos e informação que caracteriza a atual revolução tecnológica, mas a sua aplicação para a geração de conhecimentos em um ciclo de realimentação cumulativo entre inovação e uso.

A nova universalidade se constrói e se estende por meio da interconexão das mensagens entre si, sua vinculação a outras comunidades virtuais e sentidos variados que a renovam permanentemente. A Web 2.0 não decreta o fim da internet estática, mas a emergência de uma nova prática, que provoca a convivência dos dois tipos de aplicações. De acordo com Lévy (1999):

são os novos dispositivos informacionais (mundos virtuais, informações em fluxo) e comunicacionais (comunicação todos-todos) que são os maiores portadores de mutações culturais, e não o fato de que se misture o texto, a imagem e o som, como parece estar subentendido na noção vaga de multimídia (LEVY, 1999, p. 63).

A novidade é o emprego de tais dispositivos para a relação entre pessoas, estreitando laços sociais.

Assim, os meios de comunicação e a sociedade vão se desenvolvendo juntos e o termo rede já é usado tanto na perspectiva social quanto na eletrônica (MCKENNA, 1998). Os meios de comunicação exibem cada vez mais características próprias dos seres humanos e lhes permitem ser, ao mesmo tempo, mais individualistas e mais colaborativos. Os meios de comunicação ajudam a construir comunidades de interesses comuns e individuais, impactando o ambiente social.

As redes sociais virtuais são redes de intercâmbio social desenvolvidas na internet. Com o advento da Web 2.0, que ofereceu mais velocidade e facilidade de navegação, elas se popularizaram e hoje ocupam parte significativa do tempo e da atenção dos usuários na utilização da web. As redes sociais virtuais funcionam através da interação, buscando conectar pessoas e proporcionar sua comunicação. Portanto podem ser utilizadas para tecer laços sociais (RECUERO, 2007).

De acordo com Castells (1999), as redes sociais virtuais, em sua maioria, baseiam-se em laços extremamente diversificados e especializados, sendo capazes de gerar reciprocidade e apoio por intermédio da dinâmica da interação sustentada. Elas reforçam a tendência do que o autor chama de privatização da sociabilidade, isto é, a reconstrução das redes sociais ao redor do indivíduo, o desenvolvimento de comunidades pessoais. Os vínculos cibernéticos oferecem a oportunidade de vínculos sociais para pessoas que, caso contrário, viveriam vidas sociais limitadas, pois seus vínculos estão cada vez mais espacialmente dispersos.

O ciberespaço encoraja os relacionamentos, independentemente de lugares geográficos e da coincidência dos tempos, o que não chega a ser exatamente uma novidade (LÉVY, 1999). Telefone

REMark - Revista Brasileira de Marketing, São Paulo, v. 8, n. 2, p 41-54, jul./dez. 2009. 
e cartas cumpriam papel semelhante. Porém apenas as particularidades técnicas do ciberespaço permitem que os membros de um grupo humano se coordenem, cooperem, alimentem e consultem uma memória comum, praticamente em tempo real, apesar das distâncias e diferenças de horário. As ferramentas para o desenvolvimento de redes sociais na internet, majoritariamente gratuitas e de fácil uso, oferecem um espaço virtual para escrever e compartilhar conteúdos multimídia com pessoas de interesses similares, o que contribui para estreitar relações. As redes sociais virtuais estão em alta, crescendo exponencialmente a cada dia. $\mathrm{O}$ mercado mundial de aplicativos deve se expandir dos US\$ 46 milhões em 2006 para US\$ 430 milhões em 2009 (DAMASCENO, 2008). Entre as grandes redes sociais em todo o mundo incluem-se MySpace, Facebook, Hi5, Friendster, Orkut, Bebo, Tagged, Flickr e Youtube, entre outras.

Características inerentes a esse tipo de aplicativo, como facilidade de uso, aliadas ao desejo de expressão do público, começaram a chamar a atenção de empresas (COUTINHO, 2007), porém ainda são poucas aquelas que utilizam essas ferramentas em seu favor.

\section{GESTÃO COLABORATIVA DA MARCA}

Nas redes sociais virtuais, a criação e o consumo de conteúdos se transformam em um "processo unipessoal e coletivo, onde todos os participantes alimentam esta cadeia como um círculo virtuoso que potencializa o social com o tecnológico, e vice-versa" (ROMANÍ; KUKLINSKY, 2007, p. 66).

Efetivamente, a digitalização e as novas tecnologias de comunicação e informação estão mudando a natureza da mídia de massa, que deve deixar de empurrar bits para as pessoas, a fim de permitir que as pessoas (ou seus computadores) tomem tal iniciativa.

No novo cenário midiático, o mercado de comunicação precisa adaptar-se à comunicação entre consumidores, em vez de à comunicação com os consumidores, conforme preconizavam as práticas tradicionais. Já não se trata de fazer os consumidores comprarem uma marca, mas se organizarem ao seu redor. Nesse sentido, o ciberespaço encoraja uma troca recíproca e comunitária, enquanto as mídias clássicas praticam uma comunicação unidirecional, na qual os receptores estão isolados uns dos outros (LÉVY, 1999).

A ideia de conteúdo gerado pelo usuário, associada às redes sociais virtuais, costuma deixar as empresas preocupadas devido à tradição da comunicação de mão única. Coutinho (2007),

REMark - Revista Brasileira de Marketing, São Paulo, v. 8, n. 2, p 41-54, jul./dez. 2009. 
entretanto, enumera os motivos pelos quais os profissionais de marketing deveriam interessar-se pelas redes sociais virtuais:

- O envolvimento dos internautas com as redes sociais virtuais é crescente.

- As redes sociais virtuais geram impacto sobre a percepção de modernidade da marca.

- As redes sociais virtuais têm capacidade de gerar novas ideias para a comunicação mercadológica.

- As redes sociais virtuais conseguem reunir rapidamente tanto os advogados da marca como os consumidores que tiveram experiências negativas, grupos particularmente ativos na divulgação de opiniões.

- As redes sociais virtuais atuam como uma rede de early warning, indicando possíveis problemas, antes mesmo que eles se articulem como queixas/percepções.

De fato observa-se que o consumidor está mudando, exigindo, cada vez mais, produtos e serviços personalizados, que atendam especialmente a suas necessidades. Com isso, muda também a relação estabelecida com as marcas. Cada vez mais, marca e produtos não são feitos apenas para os consumidores, mas sim por eles. A internet e as redes sociais virtuais potencializam tais mudanças.

Com base nesse cenário e no conceito de aprendizagem colaborativa ou cooperativa, que prevê um modelo de ensino-aprendizagem com maior interação entre professor e aluno, repensando o modelo tradicional e unidirecional (do professor para o aluno) e sequencial (o aprendizado precedendo o trabalho), ressalta-se aqui a importância de uma gestão colaborativa da marca nas redes sociais virtuais.

De acordo com Barbosa e Serrano (2007), o conceito da aprendizagem colaborativa foi cunhado por Smyser (1993), para quem a aquisição de conhecimento se dá a partir do momento em que os alunos participam ativamente no processo de aprendizagem, como parceiros entre si e do professor. Nesse processo, ganha importância a interdependência positiva dos sujeitos envolvidos, por meio da qual cada um contribui para o processo e para o sucesso do grupo. As autoras observam que ensinar através da solução de problemas que reflitam uma perspectiva de aplicação dentro do contexto do aluno é fundamental para o processo reflexivo, uma vez que as pessoas investem mais energia nas situações que são de seu interesse.

REMark - Revista Brasileira de Marketing, São Paulo, v. 8, n. 2, p 41-54, jul./dez. 2009. 
Nesse sentido, referir-se à gestão colaborativa da marca supõe que as empresas conversem com os seus consumidores, disponibilizem canais pelos quais eles emitam sua opinião, discutam com os demais acerca da marca e ajudem a empresa a construir a marca e os seus produtos. Com efeito, as redes sociais virtuais são ambientes familiares aos consumidores, já usadas para expressar opiniões diversas, e podem também ser aproveitadas pelas empresas. Afinal, é mais fácil reunir os consumidores em um espaço onde eles já estão presentes do que fazê-los migrar para um novo software ou modelo de interação.

Ao contrário da forma unidirecional de gestão da marca, de cima para baixo, da empresa para o consumidor, o novo paradigma pressupõe que o objetivo seja fazer o que o consumidor espera da empresa e integrá-lo aos processos. E o consumidor quer ser ouvido, quer participar dos processos da empresa. Afinal, os produtos são feitos para ele (BRETZKE, 2000).

\section{CONSIDERAÇÕES FINAIS}

As bases da aprendizagem colaborativa nos modelos de hoje têm sua origem na educação à distância, existente desde o início do século XX, ainda de forma unidirecional. A aprendizagem efetivamente colaborativa só foi possível a partir do surgimento da internet e seus hiperlinks.

A internet permite a comunicação a qualquer momento, com pessoas em qualquer lugar, de modo rápido e fácil, e funciona como um repositório que propicia a construção conjunta do conhecimento, graças à possibilidade de publicar e visualizar informações, dados e documentos. Em síntese, materializa a era da interatividade em grande escala, a evolução da mídia de comunicação um a um e um a muitos para a comunicação muitos a muitos.

A partir das contribuições teóricas da aprendizagem colaborativa, sugere-se a apropriação de tais conceitos e a sua aplicação para a gestão da marca e do relacionamento com o consumidor nas redes sociais da internet, surgindo daí a proposta de gestão colaborativa da marca.

As redes sociais virtuais são ambientes naturalmente propensos às atividades de interação, discussão e construção do conhecimento coletivo. São terreno fértil para a gestão colaborativa por serem espaços nos quais o consumidor está presente e envolvido com a proposta, bem como disposto a debater e a efetivamente opinar sobre um determinado tema.

Com base na premissa da aprendizagem colaborativa, segundo a qual o aprendizado passivo que elege o professor como portador de verdades absolutas forma estudantes sem pensamento

REMark - Revista Brasileira de Marketing, São Paulo, v. 8, n. 2, p 41-54, jul./dez. 2009. 
crítico, acredita-se que a mesma relação ocorra em torno das marcas. Atualmente são escassos os consumidores desinformados, graças ao acesso sem precedentes a um número cada vez maior de informações sobre os produtos.

Objetivo da aprendizagem colaborativa, da construção conjunta do conhecimento, é fazer com que o estudante se torne mais atuante na definição do conteúdo, na sua própria formação e, consequentemente, na formação dos demais. Troca-se o processo de aprendizado passivo e isolado pelo de aprendizado ativo e coletivo.

É essa premissa que embasa a proposta de gestão colaborativa da marca: fazer mais que apenas informar o consumidor e, sim, integrá-lo aos processos em torno dos produtos, fortalecendo seu relacionamento com a empresa e com a marca. O novo modelo resulta num processo de comunicação com muitos emissores, muitos receptores e uma quantidade muito maior de intercâmbios e de cooperação.

O ambiente virtual é um espaço que permite o armazenamento, a busca e a divulgação de conteúdo de forma rápida e barata, o que torna as comunidades um repositório de opiniões, experiências e conhecimentos. Tal característica resulta na criação de capital intelectual e também de informações de marketing que aumentam o seu valor, tanto para os consumidores quanto para as empresas.

A empresa deve valorizar esse movimento e, mais do que isso, deve participar dele, já que a comunicação que se cria é de mão dupla. Deve estar atenta ao que os clientes dizem, responderlhes, aproveitar e estimular sua participação na gestão da marca, criar uma relação de confiança e torná-la cada vez mais relevante. Esse processo, além de auxiliar o consumidor a entender a organização como um todo, serve para integrá-lo aos seus processos, demonstrando a importância e o valor da sua opinião.

Por isso, é das redes sociais virtuais que emerge esse novo conceito de gestão de marca, de posicionamento e de relacionamento com o consumidor. O consumidor está abandonando a passividade, dando lugar à interatividade. Ele não quer mais apenas ouvir o que a empresa tem a dizer, mas participar das discussões.

REMark - Revista Brasileira de Marketing, São Paulo, v. 8, n. 2, p 41-54, jul./dez. 2009. 


\section{REFERÊNCIAS}

AAKER, D. Construindo marcas fortes. Porto Alegre: Bookman, 2007.

AAKER, D.; JOACHIMSTHALER, E. Como construir marcas líderes. Porto Alegre: Bookman, 2007.

AMERICAN MARKETING ASSOCIATION. Definição de marca. Disponível em: $<$ http://www.marketingpower.com/mgdictionary.php?SearchFor $=$ brand $\&$ SearchDefinitionsAlso=ON\&Searched $=1>$. Acesso em: 02 out. 2007.

BARBOSA, C.; SERRANO, C. O blog como ferramenta para construção do conhecimento e aprendizagem colaborativa. Disponível em: <http://www.abed.org.br/congresso2005/por/pdf/011tcc3.pdf>. Acesso em: 17 set. 2007.

BRETZKE, M. Marketing de relacionamento e competição em tempo real com CRM. São Paulo: Atlas, 2000.

CASTELLS, M. A sociedade em rede. São Paulo: Paz e Terra, 1999.

CENTURIÃO, A. O que é mesmo esse tal de CRM? Disponível em: <http://www.widebiz.com.br/gente/centuriao/crm.html>. Acesso em: 17 set. 2007.

COUTINHO, M. Marketing e comunidades digitais: do discurso ao diálogo. Revista da ESPM, São Paulo, v. 14, p. 28-39, 2007.

DAMASCENO, S. Crescei e multiplicai. Meio \& Mensagem, São Paulo, n. 1.315, p. 44, 2008.

ELLWOOD, I. O livro essencial das marcas: tudo o que você precisa saber, em mais de 100 técnicas para aumentar o valor das marcas. São Paulo: Clio, 2004.

KAPFERER, J. N. As marcas, capital da empresa: criar e desenvolver marcas fortes. Porto Alegre: Bookman, 2003.

KOTLER, P. Marketing de A a Z: 80 conceitos que todo profissional precisa saber. Rio de Janeiro: Campus, 2003.

KOTLER, P.; KELLER, K. Administração de marketing. São Paulo: Pearson Prentice Hall, 2006.

REMark - Revista Brasileira de Marketing, São Paulo, v. 8, n. 2, p 41-54, jul./dez. 2009. 
LÉVY, P. Cibercultura. São Paulo: 34, 1999.

MCKENNA, R. Marketing de relacionamento: estratégias bem-sucedidas para a era do cliente. Rio de Janeiro: Campus, 1992.

MCKENNA, R. Competindo em tempo real: estratégias vencedoras para a era do cliente nunca satisfeito. Rio de Janeiro: Campus, 1998.

O'REILLY, T. What is web 2.0? Design patterns and business models for the next generation of software. Disponível em: <http://www.oreillynet.com/pub/a/oreilly/tim/news/2005/09/30/whatis-Web-20.html>. Acesso em: 08 nov. 2007.

RECUERO, R. Redes sociais na Internet. Disponível em: <http://www.bocc.ubi.pt/pag/recueroraquel-redes-sociais-na-Internet.pdf>. Acesso em: 25 out. 2007.

RIES, A.; TROUT, J. Posicionamento: a batalha pela sua mente. São Paulo: Pioneira, 1996.

ROMANÍ, C. B.; KUKLINSKI, H. P. Planeta Web 2.0: Inteligencia colectiva o medios fast food. Disponível em: <http://www.planetaweb2.net/>. Acesso em: 19 set. 2007.

STONE, M.; WOODCOCK, N. Marketing de relacionamento. São Paulo: Littera Mundi, 1998.

BRAND COLLABORATIVE MANAGEMENT IN ONLINE SOCIAL NETWORKINGS

\begin{abstract}
Starting on the concept of collaborative or cooperative learning (educational process based on the collective work, on sharing information and in the interdependence of the group members), this article discusses the proposal of collaborative brand management in online social networking. In the collaborative management, the corporate communication strategy evolves from the one to many model to the many to many model, in a horizontal line of action and in a two-way direction.
\end{abstract}

Keywords: Advertising; Brand; Collaborative Management; Internet; Online Social Networking.

REMark - Revista Brasileira de Marketing, São Paulo, v. 8, n. 2, p 41-54, jul./dez. 2009. 
Data do recebimento do artigo: 15/07/2009

Data do aceite de publicação: 26/09/2009

REMark - Revista Brasileira de Marketing, São Paulo, v. 8, n. 2, p 41-54, jul./dez. 2009. 